\title{
EFFECT OF HIGH TEMPERATURE AND EXPOSURE DURATION ON STEM ELONGATION OF ICEBERG LETTUCE
}

\author{
Fahad Al-Said ${ }^{1}$, Paul Hadley², Simon Pearson², Muhammad Mumtaz Khan ${ }^{3 *}$ and Qumer Iqbal ${ }^{4}$ \\ ${ }^{1}$ The Research Council, PO Box 1422, Muscat 130, Sultanate of Oman; ${ }^{2}$ Department of Horticulture and Landscape, \\ University of Reading, School of Plant Science, Reading RG6 6SA UK; ${ }^{3}$ Department of Crop Sciences, Sultan Qaboos \\ University, PO Box 34, Alkhod 123, Sultanate of Oman; ${ }^{4}$ Fiblast, LLC. 1602 Mizell Road Tuskegee, Alabama 36083, \\ USA. \\ "Corresponding author’s e-mail: mumtaz@squ.edu.om
}

\begin{abstract}
Lettuce is a cool season vegetable that has a tendency to bolt in long day and high temperature environments. In this study, lettuce plants were exposed to two temperature transfers to evaluate the pattern of biomass accumulation, stem elongation and bolting. Plants were reciprocally transferred between two temperatures $\left(13\right.$ and $\left.25^{\circ} \mathrm{C}\right)$. A negative co relation was found between the temperature and shoot growth as well as dry weight. However, stem extension was positively correlated with high temperature. Lettuce plants had $46 \%$ higher shoot fresh weights at a constant temperature of $13^{\circ} \mathrm{C}$, than those grown at a constant $25^{\circ} \mathrm{C}$. The positive correlation between high temperature and stem elongation was a function of the duration of exposure to high temperature. However, bolting was distinguishable from stem elongation. Overall results indicated that plants could revert back to head formation even after two weeks of high temperature-induced stem elongation. However, constant exposure to high temperature causes bolting without head formation.
\end{abstract}

Keywords: Lettuce, head formation, heat, stem extension, transfer time.

\section{INTRODUCTION}

Lettuce is the one of the most important leafy vegetable crop produced for fresh market. The breeders have been selecting cultivars suited for heat stress environments since exposure to high temperature induces bolting in most lettuce cultivars. Physiologically, it is imperative to investigate the precise relationship between head formation and the bolting processes under changing temperature regimes. This could provide suitable cultivars selection indices as well as assist crop management when growing lettuce under relatively hot climates. The effect of the growing environment during the head formation process in iceberg lettuce is crucial, since this determines the final head size and its quality. Larger head weights and decreased fresh lettuce weights are associated with low temperatures during and around heading but high temperature reduce the time to maturity (Choi et al., 2004; Thompson et al., 1998; Wurr et al., 1996).

There are five major types of lettuce based on head formation or leaf type. First one is iceberg lettuce also known as crisp head. It has tight head of crisp leaves and susceptible to high temperature, bolting, water stress and rottening. Batavian or summer crisp or French crisp is the second type that is in between crisp head and loose leaf types of lettuce while resistant to bolting. Third type of lettuce is butter head or Boston or bib. It is creamy to light green from inside and loose, soft and tangled green from outside. Less likely to bolt and rarely bitter. Romaine or Cos is the fourth type that grow straight and have spoon shaped tightly folded leaves. Fifth one is loose leaf also called leaf, cutting or bunching that has no head or heart formation. Loose leaves are directly used as lettuce. It is slow bolting type of lettuce (Grant, 2016). Bolting occurs when vegetables or herbs shift from vegetative phase (leafy stage) to reproductive phase (seed formation stage) (Rhoades, 2016). Exposure to high temperatures late in the growing season, lettuce may bolt causing bitterness loose fluffy heads, and tip burn is also common (Fukuda et al., 2009; Jackson et al., 1996a; Jackson et al., 1996b). Higher temperature accelerated the lettuce stem elongation that also severely affect its yield, quality and marketability (Fukuda $e t$ al., 2012; Rader and Karlsson, 2006; Zhao et al., 2003) but it's also strictly cultivar dependent (Zhao and Carey, 2009). Whether the influence of high temperature on growth and stem extension is instantaneous or there is a carry-over effect that results in bolting requires further study. The effect of high temperature exposure time on elongation, and the developmental stage of the plant at which the exposure to high temperature is applied, also requires elucidation. Elongation of stems was promoted and the formation of compact heads was absent in plants whose roots were exposed to high diurnal ambient temperature (He and Lee 1998). A relatively high rate of leaf production associated with low rate of stem elongation is necessary in the head formation process in lettuce (Dufault et al., 2009). The rate of leaf production increases with an increase in temperature but it may also cause loose leaf structure with the leaves acquiring a bitter taste 
(Decoteau, 2000). Keeping in view the impact of different temperature regimes on productive and qualitative traits of lettuce, present study was conducted to assess the effect of high temperature on stem extension rate and to determine whether the effect is reversible. Similarly, the effect of exposure duration to high temperature on stem elongation was also investigated.

\section{MATERIALS AND METHODS}

Experiment I: Seeds of iceberg lettuce (Lactuca sativa var. Capitata L., cv. Saladin Supreme) susceptible to bolting were sown and raised at $17^{\circ} \mathrm{C}$ in a factorial arrangement in the glasshouse, University of Reading, UK. Four weeks later, at the fourth leaf stage 84 seedlings were potted in $1.0 \mathrm{~L}$ pots containing a mixture of vermiculite, sand and gravel $(2: 1: 2$ $\mathrm{V} / \mathrm{V})$, and placed into two glasshouse compartments set to provide constant temperatures of $13^{\circ} \mathrm{C}$ and $25^{\circ} \mathrm{C}(42$ plants/compartment) under natural day length. Ventilation occurred at $4^{\circ} \mathrm{C}$ higher than the set point temperatures. One week after transplanting and every 5 days thereafter for a further 25 days, three replications of 2 plants each were transferred reciprocally from one temperature to the other. After the final transfer (32 days), the plants were left to grow until day 42, and then harvested. Plants were irrigated automatically 4 times a day with a diluted nutrient solution (Sangral 1:1:1, $182 \mathrm{ppm} \mathrm{N;} 78 \mathrm{ppm} \mathrm{P}$ and $150 \mathrm{ppm} \mathrm{K}$ ) to a conductivity of $1500 \mu \mathrm{S} \mathrm{cm}-1$ and acidified to a $\mathrm{pH}$ of 5.8 . Temperature within the compartments was recorded with a data logger (Datataker 500, Data Electronics Ltd, UK) scanning every 15 seconds and recording hourly averages using PT100 temperature sensors. Plants were cut at hypocotyl for shoot fresh and dry weight, and stem length assessment. Stem length measurements were used to assess bolting in plants (assumed to have occurred when plants attained a $100 \mathrm{~mm}$ stem length). This was measured from the cotyledon to the apex. After recording fresh weight and stem length, each group of leaves and stem were put in separate paper bags, and then placed in a forced air oven to dry at $\sim 80^{\circ} \mathrm{C}$ for 4 days.

Experiment II: Plants were placed in three glasshouse compartments set to provide constant temperatures of 10, 19 and $28^{\circ} \mathrm{C}$. At each temperature, four replications of 2 plants each were left to grow without transfer throughout the experimental period to provide controls. The $19^{\circ} \mathrm{C}$ treatment was used as an optimum temperature for growth and heading. The $10^{\circ} \mathrm{C}$ treatment was used as a slow growing treatment to examine enhanced head formation. The $28^{\circ} \mathrm{C}$ treatment was used to provide a conducive temperature for stem elongation and bolting (Fig. 1).

A further twelve replications of 2 plants each were allowed to grow at $19^{\circ} \mathrm{C}$ for two weeks and then transferred to $28^{\circ} \mathrm{C}$. Following transfer to $28^{\circ} \mathrm{C}$, plants were left to grow for 1,2 or 3 weeks respectively before being transferred to $10^{\circ} \mathrm{C}$ (four replications of 2 plants per transfer) in order to determine whether heads could be formed post-bolting. After the final transfer to $10^{\circ} \mathrm{C}$, plants were allowed to grow for a further week. Irrigation was carried out as described in experiment I. At harvest, stem length as well as shoot fresh and dry weights were recorded as described above.

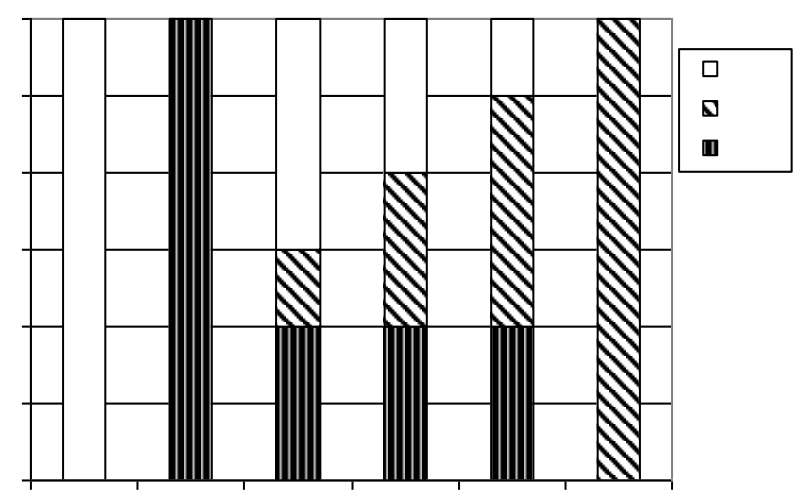

Figure 1.Different temperature treatments during experiment II obtained from transfer between 19, 28 and $10^{\circ} \mathrm{C}$. Treatments $A, B$ and $F$ were controls grown for the entire experiment period at 10,19 and $28^{\circ} \mathrm{C}$. Treatments $\mathrm{C}, \mathrm{D}$ and $\mathrm{E}$ were grown for 2 weeks at $19^{\circ} \mathrm{C}$ and then transferred to $28^{\circ} \mathrm{C}$. These were then further transferred to 10 from $28^{\circ} \mathrm{C}$ after 1,2 and 3 weeks at $28^{\circ} \mathrm{C}$ respectively. There were 8 plants per transfer.

Statistical analysis: Experiments were conducted using a completely randomized design. Data were analysed using SAS (version 6.12). Analyses of variance (5\% level) were used to compare data of different treatments, followed by estimation of the Least Significant Difference (LSD) among the individual treatment means (Steel et al., 1997). Exponential regression was used to fit the equation.

$$
\mathrm{Y}=a b^{\mathrm{x}}(\mathrm{a} \neq 0)
$$

\section{RESULTS}

\section{Experiment I:}

Shoot fresh and dry weight (g): Shoot fresh weight and dry weight were significantly affected by growing temperature $(\mathrm{P} \leq 0.001)$. Plants grown continuously at $13^{\circ} \mathrm{C}$ had $46 \%$ higher shoot fresh weight than plants grown at $25^{\circ} \mathrm{C}(311.2$ and $215.7 \mathrm{~g}$, respectively). The effect on dry weight was similar (19.4 and 12.9g). Shoot fresh and dry weights were also highly affected by the duration of the exposure period to growing temperature $(\mathrm{P} \leq 0.001)$ (Fig $2 \& 3)$. Reciprocal transfers to $13^{\circ} \mathrm{C}$ and $25^{\circ} \mathrm{C}$ showed an inverse relationship. At $13^{\circ} \mathrm{C}$ and up to the 22 day transfer, negative correlation was observed between shoot fresh and dry weight and 
duration of temperature exposure. Shoot fresh weight was $388.9 \mathrm{~g}$ for plants transferred on day 7 while it was $302.4 \mathrm{~g}$ for plants transferred on 22 days. Similarly, shoot dry weight was $22.6 \mathrm{~g}$ and $16.4 \mathrm{~g}$ for plants transferred on day 7 and 22, respectively (Fig. $2 \& 3$ ). In contrast, shoot fresh and dry weight of plants grown at $25^{\circ} \mathrm{C}$ at the end of the experiment showed an inverse relationship to that of $13^{\circ} \mathrm{C}$. Shoot fresh and dry weight of plants increased up to the 22 day transfer (161.2 and $273.1 \mathrm{~g} ; 11.1$ to $14.8 \mathrm{~g}$ for 7 and 22 days transfers, respectively). The difference in shoot fresh and dry weight of plants diminished for the 22 day onward transfers.

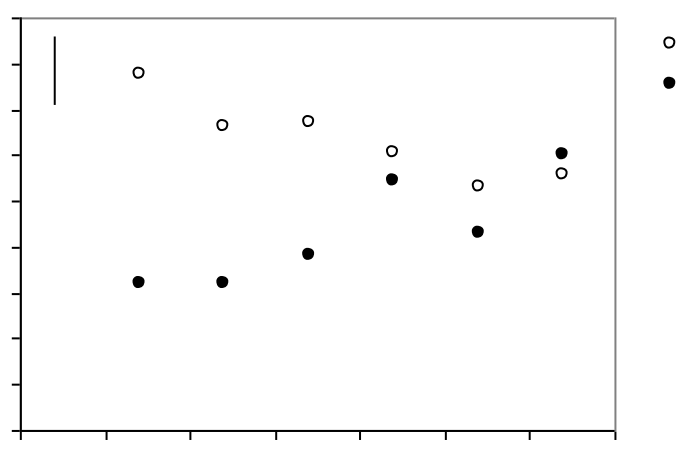

Figure 2. The effect of reciprocal transfer at various days after transplanting between two growing temperatures $\left(13\right.$ and $\left.25^{\circ} \mathrm{C}\right)$ on fresh weight.•, plants that started at $13^{\circ} \mathrm{C}$ and were transferred to $25^{\circ} \mathrm{C}$; $\circ$, plants that started at $25^{\circ} \mathrm{C}$ and were transferred to $13^{\circ} \mathrm{C}$. The vertical bar indicates the LSD at $5 \%(69.9)$.

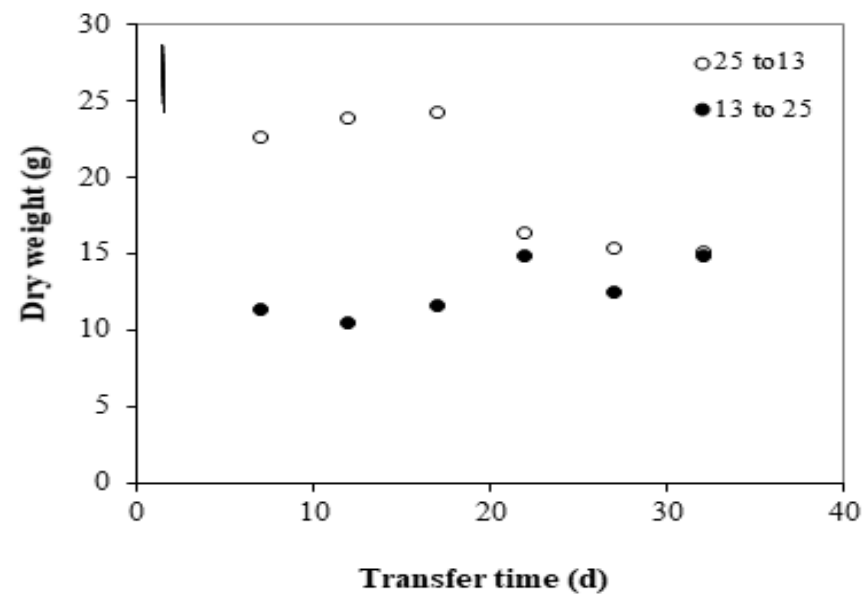

Figure 3. The effect of reciprocal transfer at various days after transplanting between two growing temperatures $\left(13\right.$ and $\left.25^{\circ} \mathrm{C}\right)$ on dry weight.•, plants that started at $13^{\circ} \mathrm{C}$ and were transferred to $25^{\circ} \mathrm{C}$; $\circ$, plants that started at $25^{\circ} \mathrm{C}$ and were transferred to $13^{\circ} \mathrm{C}$. The vertical bar indicates the LSD at $5 \%$ (4.05).
Stem length ( $\mathbf{m m})$ : Stem length increased as a positive function of the high temperature exposure period (Fig. 4). Stem length of plants transferred to $13^{\circ} \mathrm{C}$ increased exponentially with transfer time from $25^{\circ} \mathrm{C}(66.2$ to 302.5 $\mathrm{mm})$. Data were quantified using exponential regression. Stem length $=44.336 \mathrm{e}^{0.0628 \mathrm{t}} \mathrm{T}$, where $\mathrm{t}_{\mathrm{T}}$ is transfer time in days This relationship accounted for $98 \%$ of the variation of stem length in relation to transfer time from 25 to $13^{\circ} \mathrm{C}$. Stem length decreased exponentially with increasing transfer time from 13 to $25^{\circ} \mathrm{C}$, where stem length $=379.94 \mathrm{e}^{-0.0459 \mathrm{t}} \mathrm{T}$ $\left(\mathrm{R}^{2}=0.99\right)$.

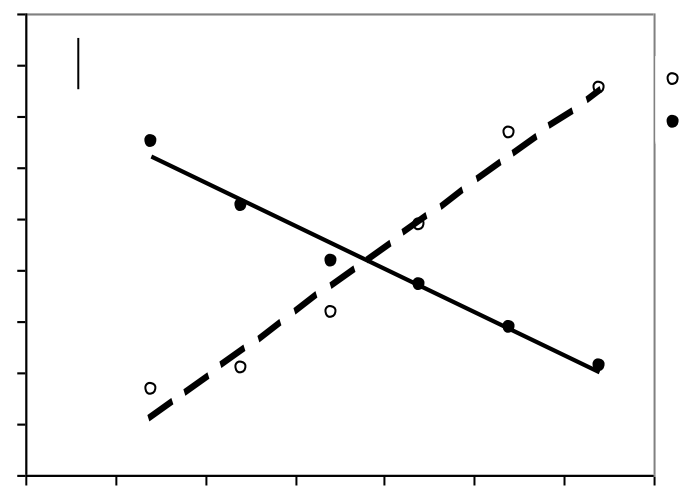

Figure 4. Stem length as affected by reciprocal transfer at various days after transplanting between two growing temperatures. $\bullet$, Plants that started at $13^{\circ} \mathrm{C}$ and transferred to $25^{\circ} \mathrm{C} ; \circ$, Plants that started at $25^{\circ} \mathrm{C}$ and transferred to $13^{\circ} \mathrm{C}$. The lines were fitted by linear regression for $13^{\circ} \mathrm{C}$ data (solid line) and $25^{\circ} \mathrm{C}$ data (broken line) at the end of the experiment, where the stem length is $10.287( \pm 0.867) \mathrm{t}_{\mathrm{T}}-26.978( \pm 18.466)\left(\mathrm{r}^{2}=0.97\right.$, 5 d.f. $)$, and $295.309( \pm 9.718)-6.727( \pm 0.457) \mathrm{t}_{\mathrm{T}}\left(\mathrm{r}^{2}=0.98\right.$, 5 d.f) respectively. The vertical bar indicates the LSD at $5 \%$ (43.4).

In order to model the effect of actual growing mean temperature on stem elongation, data were combined and plotted against actual growing mean temperatures which were calculated as follows:

$$
\mathrm{MT}=\left(\mathrm{DD}_{13^{\circ} \mathrm{C}}+\mathrm{DD}_{25^{\circ} \mathrm{C}}\right) / \mathrm{t}_{\mathrm{expt}}
$$

Where MT is mean growing temperature in ${ }^{\circ} \mathrm{C}$, DD is thermal time at $13^{\circ} \mathrm{C}$ and $25^{\circ} \mathrm{C}$ temperature in ${ }^{\circ} \mathrm{Cd}$, and $t_{\exp }$ is the experiment duration in days.

There was a non-linear relationship between stem length and mean growing temperature best described by a power function where stem length $=0.0089 \mathrm{MT}^{3.2817}$, while $\mathrm{MT}$ is the actual mean growing temperature in ${ }^{\circ} \mathrm{C},\left(\mathrm{R}^{2}=0.96\right.$, Fig. 5).

Stem elongation was therefore a positive function of the duration of exposure to high temperature. Bolting was also promoted by longer periods of high temperature exposure. Except those transferred after 32 days, plants transferred from 
the low growing temperature to the higher temperature had bolted at the end of the experiment. Plants that were transferred to the lower temperature from the higher temperature from 17 days onwards bolted.

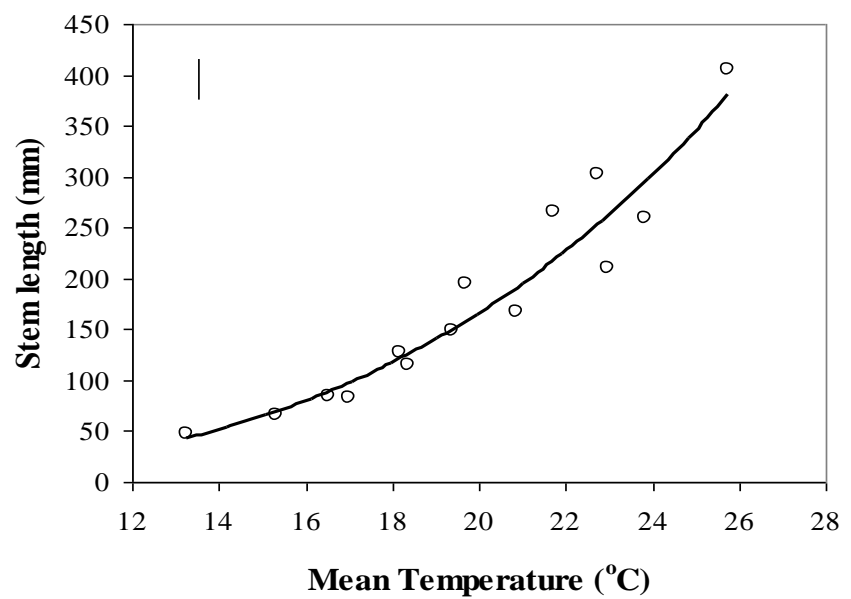

Figure 5.Stem length as affected by mean growing temperature recorded from start of experiment until the harvest time. The curve was fitted by power curve where stem length is $0.0089 \mathrm{MT}^{3.284}\left(\mathrm{r}^{2}=0.95,13\right.$ d.f.). The vertical bar indicates the LSD at $5 \%$ (43.4).

\section{Experiment II:}

Shoot fresh and dry weight (g): Shoot fresh and dry weight was significantly affected by the growing temperature. Fresh and dry weight of shoots decreased linearly with increased exposure time at $28^{\circ} \mathrm{C}(\mathrm{P} \leq 0.001$, Figure $6 \& 7)$.

Maximum shoot fresh and dry weight was achieved in plants grown at $19^{\circ} \mathrm{C}(481.7$ and $27.1 \mathrm{~g}$, respectively) for the whole experimental period. While plants that were grown at 10 and $28^{\circ} \mathrm{C}$ for the whole experimental period achieved almost the same shoot fresh weight (102.4 and $106.8 \mathrm{~g}$, respectively); however, greater shoot dry matter accumulation was in plants grown under $28^{\circ} \mathrm{C}$ rather than $10^{\circ} \mathrm{C}(12.4$ and $8.3 \mathrm{~g}$, respectively). Plants grown under the higher temperature bolted and did not form heads. On the other hand, the slow growth of plants at $10^{\circ} \mathrm{C}$ resulted in the formation of heads.

Temperature transfers also affected plant fresh and dry weights. Plants achieved higher fresh and dry weights when they were transferred from 28 to $10^{\circ} \mathrm{C}$. The increase in shoot fresh and dry weight was a negative function of exposure time at $28^{\circ} \mathrm{C}$.

The plant's ability to continue the head formation process irrespective of previous high growing temperature was reflected in increased shoot weight. Although plants exposed to high temperature $\left(28^{\circ} \mathrm{C}\right)$ for one week were considered to have bolted $(99.5 \mathrm{~mm})$ at the end of the experiment, shoot fresh weight increased sharply $(316.5 \mathrm{~g})$ indicating a continuation of the head formation process. However, the effect of initial low temperature on head formation process did not reduce the effect of subsequent high temperatures in accelerating the progression of plants towards bolting (169 and $242.3 \mathrm{~mm}$ ), despite the increased shoot fresh weight (223.3 and $160 \mathrm{~g})$.

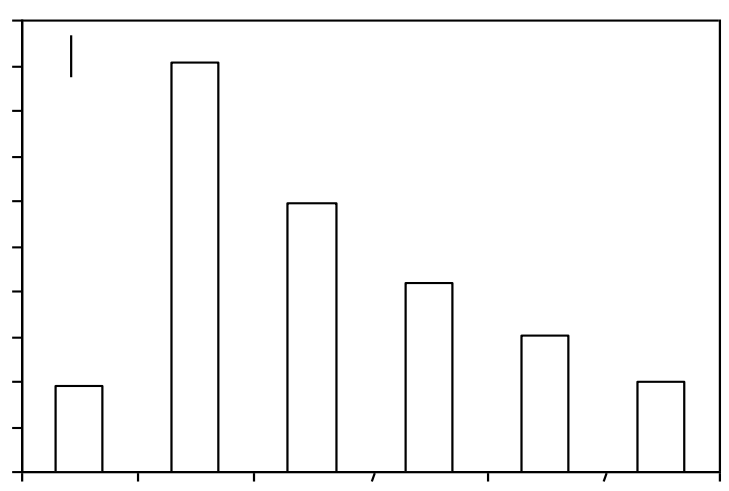

Figure 6. Plant fresh weight as affected by temperature transfer treatments between 10,19 and $28^{\circ} \mathrm{C}$. Treatments $\mathrm{A}$, $\mathrm{B}$ and $\mathrm{F}$ were controls grown for the entire experiment period at 10 , 19 and $28^{\circ} \mathrm{C}$. Treatments $\mathrm{C}, \mathrm{D}$ and $\mathrm{E}$ were grown for 2 weeks at $19^{\circ} \mathrm{C}$ and then transferred to $28^{\circ} \mathrm{C}$. These were then, further transferred to 10 after 1,2 and 3 weeks at $28^{\circ} \mathrm{C}$ respectively. The vertical bar indicates the LSD at 5\% (53.1).

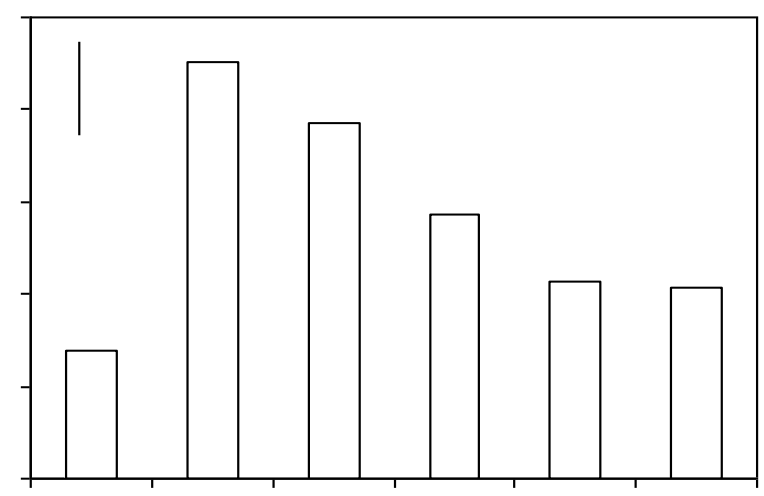

Figure 7.Plant dry weight as affected by temperature transfer treatments between 10,19 and $28^{\circ} \mathrm{C}$. Treatments A, B and $\mathrm{F}$ were controls grown for the entire experiment period at 10,19 and $28^{\circ} \mathrm{C}$. Treatments C, D and $\mathrm{E}$ were grown for 2 weeks at $19^{\circ} \mathrm{C}$ and then transferred to $28^{\circ} \mathrm{C}$. These were then, further transferred to 10 after 1,2 and 3 weeks at $28^{\circ} \mathrm{C}$ respectively. The vertical bar indicates the LSD at 5\% (6.44).

Stem length (mm): Stem length at $10^{\circ} \mathrm{C}$ was a positive function of the duration of exposure to high temperatures $(\mathrm{P} \leq 0.001)$; the longer the exposure time, the greater the stem 
length (Fig. 8). The lowest stem length occurred in plants grown at $10^{\circ} \mathrm{C}$ throughout the growing period $(31.6 \mathrm{~mm})$, whilst plants raised under the highest temperature for the whole of the experimental period had the highest stem length $(382.1 \mathrm{~mm})$. Plant stem length increased with mean growing temperature. The relationship between the mean growing temperature and stem length is shown in Figure 9 where stem length $=0.1037 \mathrm{MT}^{2.4818}, \mathrm{R}^{2}=0.99$.

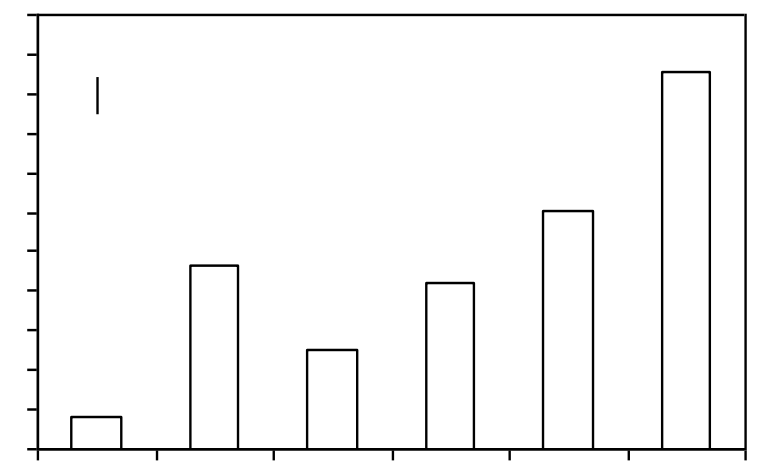

Figure 8. Stem length as affected by temperature transfer treatments between 10,19 and $28^{\circ} \mathrm{C}$. Treatments $\mathrm{A}, \mathrm{B}$ and $\mathrm{F}$ were controls grown for the entire experiment period at 10,19 and $28^{\circ} \mathrm{C}$. Treatments $\mathrm{C}, \mathrm{D}$ and $\mathrm{E}$ were grown for 2 weeks at $19^{\circ} \mathrm{C}$ and then transferred to $28^{\circ} \mathrm{C}$. These were then, further transferred to 10 after 1,2 and 3 weeks at $28^{\circ} \mathrm{C}$ respectively. The vertical bar indicates the LSD at $5 \%(43.1)$.

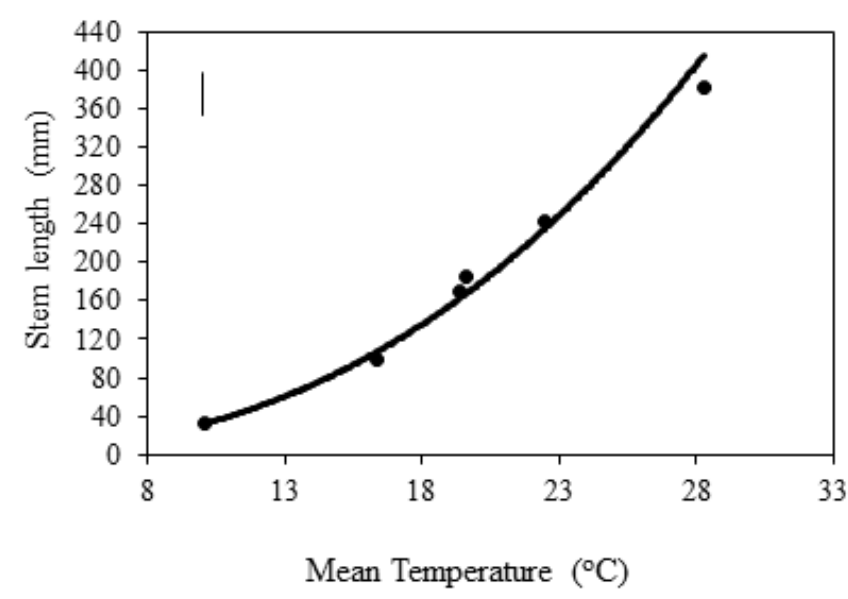

Figure 9.Stem length as affected by mean growing temperature of transfer treatments between 10 , 19 and $28^{\circ} \mathrm{C}$. A power function was fitted where stem length is $0.1037 \mathrm{MT}^{2.4818}\left(\mathrm{r}^{2}=0.99,5\right.$ d.f $)$. The vertical bar indicates the LSD at $5 \%$ (43.1).

\section{DISCUSSION}

Transferring plants between high and low temperatures provides a useful method for quantifying the effect of the duration and timing of exposure to high growing temperature on the stem extension process (Fukuda et al., 2009). Present results revealed that both the length of the exposure period to high temperature and the stage of exposure affected fresh and dry weight. The ability of a lettuce plants to form head after exposure to high temperature decreased with the advancement of the developmental stage at which they were transferred to cooler conditions. These results are in line with findings of Dufault et al. (2009) that temperature is the major environmental factor affecting production with specific stresses, such as periods of hot days, overall growing season climate, minimum and maximum daily temperatures, and timing of stress in relationship to developmental stages having the greatest effect.

Plants exposed to a higher temperature at an early stage and for a short time before transfer to a lower growing temperature environment showed increased fresh weight. The growth as indicated by weight gain under high temperature decreased sharply with time, whilst under lower temperatures, weight gain also declined with time but to a much lesser extent and was sustained for a longer period than at higher temperature. This resulted in higher weight accumulation. Consequently, an increase in transfer time to lower temperatures resulted in reduced weight gain. On the other hand, plants transferred to higher temperatures showed increased growth in the early transfers; as reflected in shoot fresh and dry weight differences between the high and low growing temperatures. However, this effect diminished with the increase of transfer time. This was confirmed by the ability of the plants to achieve higher shoot fresh and dry weights once they were transferred from high to low temperature at an early stage of growth (Experiment 1). However, the ability of the plants to gain weight decreased with the progression of development, where the fresh weight achieved was a negative function of exposure time to high temperature. High temperatures are often limiting to lettuce production with rapid inflorescence development and cut down vegetative period significantly which results in unmarketable plants (Dufault et al., 2006). These results are supported by Wheeler et al. (1993) that lettuce relative growth rate decreased with time but the rate of decrease was faster at higher temperatures. This could therefore explain why the dry weight was highest at $19^{\circ} \mathrm{C}$ and lowest at $10^{\circ} \mathrm{C}$. Thus, plants grown at the warmer temperatures achieved higher dry matter accumulation in the early stages of growth, but final dry matter accumulation was higher under moderate mean growing temperatures.

Stem extension rate was directly related to mean temperature. The reciprocal transfer experiment confirmed previous results in which stem extension rate was reduced under lower temperature conditions. Although stem length was strongly 
correlated with mean growing temperature, the final stem length was reduced even after transfer to lower temperature due to the reduction in stem extension rate. However, no significant differences were observed between plants transferred from 25 to $13{ }^{\circ} \mathrm{C}$ during the early stages of growth (days 7 and 12) and those transferred from 13 to $25^{\circ} \mathrm{C}$ at the final stages of growth (days 27 and 32). This can be attributed to higher initial stem extension rate of plants exposed to higher temperature.

The effect of high temperature on the rate of stem extension was also reflected in the ability of plants to resume the head formation process once they were transferred from high to low temperature. Once plants reached the physiological bolting stage their tendency to form a head stopped even though the rate of stem extension was slowed at the lower temperatures. Transferring plants from $28^{\circ} \mathrm{C}$ after 2 weeks to $10^{\circ} \mathrm{C}$ (Treatment D) resulted in increased fresh weight but to a lesser extent than those grown at $19^{\circ} \mathrm{C}$ (Treatment B) for the entire experimental period (control plants, Fig. 3), even though they had similar mean growing temperatures and stem lengths (Fig. 5).

The effect of high temperature on shoot fresh and dry weights was similar to results reported elsewhere. Results obtained from the reciprocal temperature transfers agree with the findings of Dufault et al. (2009) reported that high temperature accelerates premature bolting and prevents head formation in lettuce. However, stem extension and bolting are two different processes that are accelerated by high temperature. Stem extension is associated with vegetative growth that controls head density. On the other hand, bolting is a developmental process that ends in flower initiation.

The effect of growing temperature on stem extension rate is supported by the findings of Dufault et al. (2009) that lettuce stems grown at higher temperatures elongated rapidly from 2 to 4 weeks after transplanting than grown at lower temperatures. Present results revealed that high temperature induced bolting in lettuce and head formation requires a slow rate of stem elongation. Wurr et al. (1992) reported that head density in the Saladin cultivar was associated with low temperatures during the periods up to and around head formation. This can be explained on the basis of a low rate of stem extension resulting in a higher head density at lower temperatures. It also explains the formation of "puffy" heads under field conditions in warm growing seasons and compacted heads produced in cooler seasons. Thus head density is a function of stem extension. Results generated from these experiments provide a clear explanation of the effects of high temperatures on head formation and quality experienced in the field during summer season. Plants exposed to high temperature for short periods during the early stages of growth have longer stems, but the head formation process will continue normally once a normal growing temperature is regained as long as the plants had not reached the physiological bolting stage. This is confirmed by the findings of Al-Said (2000) who reported that plants formed good heads even when grown initially at abnormally high temperature regimes, indicating the ability of iceberg lettuce to retain normal growth under environments that are not conducive to bolting. This has direct implications for introducing lettuce as a crop in areas with prolonged durations of hot weathers, such as the Middle East like Oman. Nursery plants could be raised under ambient high temperatures towards the end of hot summer weather. There is a considerable overlapping period (1-2 weeks) during which the seedling will retain its ability to resume head formation even after initial high temperature- induced stem elongation.

Conclusion: Exposure duration of lettuce plants to high temperature at different stages significantly reduced biomass accumulation but positively correlated for stem elongation in iceberg lettuce. Overall results indicated that plants with elongated stems prior to bolting had the ability to resume head formation when exposed to temperatures between $10-17^{\circ} \mathrm{C}$ following high temperatures. However, further work is needed on the role of temperature on stem extension rate as well as the ability of the plants to continue the head formation process and to form a head also needs to be investigated in relation to physiological stages of plants.

Acknowledgements: We are highly grateful for the support of Sultan Qaboos University, Oman.

\section{REFERENCES}

Al-Said, F.A. 2000. The effect of temperature on the growth, stem extension and bolting in iceberg lettuce (Lactuca sativa L.). PhD diss., University of Reading, UK.

Choi, K.Y. and Y.B. Lee. 2004. Effect of air temperature on tip burn incidence of butterhead and leaf lettuce in a plant factory. J. Am. Soc. Hort. Sci. 44:805-808.

Decoteau, D. 2000. Vegetable Crops. Prentice Hall, Upper Saddle River, New Jersey.

Dufault, R., B. Ward and R.L. Hassell. 2006. Planting date and romaine lettuce cultivar affect quality and productivity. HortScience 41:640-645.

Dufault, R., B. Ward and R.L. Hassell. 2009. Dynamic relationships between field temperatures and romaine lettuce yield and head quality. Sci. Hortic. 120:452-459.

Fukuda, M., S. Matsuo, K. Kikuchi, W. Mitsuhashi, T. Toyomasu and I. Honda. 2009. The endogenous level of $\mathrm{GA}_{1}$ is upregulated by high temperature during stem elongation in lettuce through LsGA3ox1 expression. J. Plant Physiol. 166:2077-2084.

Fukuda, M., S. Matsuo, K. Kikuchi, W. Mitsuhashi, T. Toyomasu and I. Honda. 2012. Gibberellin metabolism during stem elongation stimulated by high temperature in lettuce. Acta Hort. 932:359-364. 
Grant, A. 2016. Different lettuce types: Varieties of lettuce for the garden. Available online at https://www.gardeningknowhow.com/edible/vegetables/ lettuce/different-lettuce-types.htm

He, J. and S.K. Lee. 1998. Growth and photosynthetic responses of three aeroponically grown lettuce cultivars (Lactuca sativa L.) to different root zone temperatures and growth irradiances under tropical aerial conditions. J. Hort. Sci. Biotechnol. 73:173-180.

Jackson, L., K. Mayberry, F. Laemmlen, S. Koike, K. Schulbach and W. Chaney. 1996a. Iceberg lettuce production in California. University of California, Division of Agriculture and Natural Resources. Publication 7215. Available on-line at http:// anrcatalog.ucdavis.edu/pdf/7216.pdf

Jackson, L., K. Mayberry, F. Laemmlen, S. Koike, K. Schulbach and W. Chaney. 1996b. Leaf lettuce production in California. University of California, Division of Agriculture and Natural Resources Publication 7216. Available on-line at http:// anrcatalog.ucdavis.edu/pdf/7216.pdf

Rader, H.B. and M.G. Karlsson. 2006. Northern field production of leaf and romaine lettuce using a high tunnel. HortTechnology 16:649-654.

Rhoades, H. 2016. What is bolting: What it means when a plant bolts? Available online at https://www. gardeningknowhow.com/edible/vegetables/vgen/whatis-bolting-what-it-means-when-a-plant-bolts.htm
Steel, R.G.D., J.H. Torrie and D.A. Dickey. 1997. Principles and Procedures of Statistics: A biometrical approach, $2^{\text {nd }}$ Ed. McGraw Hill Book Co., New York.

Thompson H.C., R.W. Langhans, A. Both and L.D. Albridght. 1998. Shoot and root temperature effects on lettuce growth in a floating hydroponic system. J. Am. Soc. Hort. Sci. 123:361-364.

Wheeler, T.R., P. Hadley, J.I.L. Morison and R.H. Ellis. 1993. Effects of temperature on the growth of lettuce (Lactuca sativa L.) and the implications for assessing the impacts of potential climate change. Eur. J. Agron. 2:305-311.

Wurr, D.C.E. J.R. Fellows and K. Phelps. 1996. Investigating trends in vegetable crop response to increasing temperature associated with climate change. Sci. Hortic. 66:255-263.

Wurr, D.C.E., J.R. Fellows and A.J. Hambidge. 1992. Environmental factors influencing head density and diameter of crisp lettuce cv. Saladin. J. Hortic. Sci. 67:395-401.

Zhao, X., E.E. Carey and M. Hall. 2003. Influence of protected environment and fertilizer source on growth and quality of lettuce and leafy greens during summer production in Kansas. HortScience 38:749-.

Zhao, X. and E.E. Carey. 2009. Summer production of lettuce, and microclimate in high tunnel and open field plots in Kansas. HortTechnology 19:113-119. 